\title{
In situ total aortic arch replacement for infected distal aortic arch aneurysms with penetrating atherosclerotic ulcer
}

\author{
Kenji Okada, MD, PhD, ${ }^{\mathrm{a}}$ Katsuhiro Yamanaka, MD, ${ }^{\mathrm{a}}$ Toshihito Sakamoto, MD, ${ }^{\mathrm{a}}$ Takeshi Inoue, MD, \\ Masamichi Matsumori, MD, PhD, ${ }^{a}$ Fumi Kawakami, MD, ${ }^{b}$ and Yutaka Okita, MD, $\mathrm{PhD}^{\mathrm{a}}$
}

\begin{abstract}
Background: We present a series of patients who underwent in situ total aortic arch replacement for infected distal aortic arch aneurysms.

Methods: Between 2002 and 2013, 9 patients with infected distal aortic arch aneurysms underwent total aortic arch replacement using antegrade selective cerebral perfusion. There were 4 male and 5 female patients with a mean age of $72.7 \pm 9.0$ years. All patients had penetrating atherosclerotic ulcer in the distal aortic arch, which formed saccular aneurysms. Four patients had preoperative hoarseness. Maximum preoperative white blood cell count was $10,211 \pm 4375 / \mu \mathrm{L}$, and mean serum C-reactive protein concentration was $12.7 \pm 7.2 \mathrm{mg} / \mathrm{dL}$. Causative microorganisms were identified by blood culture or aortic wall culture and were as follows: Candida albicans, Pseudomonas aeruginosa, Edwardsiella tarda, Streptococcus dysgalactiae, Listeria monocytogenes, Staphylococcus aureus (2 cases), and unknown (2 cases). Radical debridement with in situ total aortic arch replacement was performed in all patients, followed by the omental flap grafting in 7 patients. All surgery was performed on an urgent or emergency basis.
\end{abstract}

Results: Average cardiopulmonary bypass time and lower body circulatory arrest time were $199.7 \pm 50.7$ minutes and $66.6 \pm 13.8$ minutes, respectively. There was no in-hospital mortality, but 1 patient died of asphyxia 5 months after hospital discharge. Freedom from recurrence of infection was $100 \%$.

Conclusions: Surgical treatment with the combination of radical debridement with in situ total aortic arch replacement using antegrade selective cerebral perfusion and omental flap grafting was a reliable procedure for the treatment of infected distal aortic arch aneurysms. (J Thorac Cardiovasc Surg 2014;148:2096-100)

Although treatments of aortic arch aneurysm have been improving during the past decade, ${ }^{1,2}$ infected aneurysms are one of the most intractable aortic pathologies, which complicate the surgical procedure and might cause recurrence of infection with high mortality. Controversy continues over the role of in situ reconstruction, ${ }^{3}$ extra-anatomic bypass, ${ }^{4}$ or thoracic endovascular aortic repair (TEVAR), ${ }^{5-7}$ and there are few studies that have focused on the reconstruction of infected aortic arch aneurysms. We describe a series of cases treated with radical debridement of infected aortic walls followed by in situ reconstruction combined with omental flap grafting and advanced antibiotic therapy based on sensitivity data.

From the Division of Cardiovascular Surgery, ${ }^{\mathrm{a}}$ Departments of Surgery, and

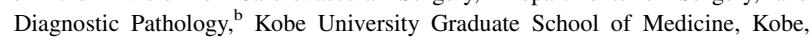
Japan.

Disclosures: Authors have nothing to disclose with regard to commercial support.

Received for publication Oct 14, 2013; revisions received Dec 22, 2013; accepted for publication Feb 3, 2014; available ahead of print March 4, 2014.

Address for reprints: Yutaka Okita, MD, PhD, Division of Cardiovascular Surgery, Department of Surgery, Kobe University Graduate School of Medicine, 7-5-2, Kusunoki-Cho, Chuo-Ku, Kobe, Hyogo 650-0017, Japan (E-mail: yokita@med. kobe-u.ac.jp).

$0022-5223 / \$ 36.00$

Copyright $(2014$ Published by Elsevier Inc. on behalf of The American Association for Thoracic Surgery

http://dx.doi.org/10.1016/j.jtcvs.2014.02.015

\section{MATERIALS AND METHODS}

A retrospective review of the cardiovascular surgical database at Kobe University Graduate School of Medicine was performed for the period from January 2002 to August 2013. The medical records were reviewed for preoperative risk factors, operative records, intraoperative events, and postoperative course. This retrospective study was approved by the institutional review board at Kobe University (\#1490). The need for individual consent was waived. During the period noted, consecutive 423 patients underwent total aortic arch replacement (TAR) using antegrade selective cerebral perfusion through a median sternotomy, and 9 $(2.1 \%)$ of them with a mean age of $72.7 \pm 9.0$ years had infected aortic arch aneurysms. The diagnosis of infected aneurysms was made by a combination of clinical presentation, blood test, computed tomography (CT) imaging, positive bacterial growth on blood/aortic tissue culture, intraoperative Gram staining, and inflammatory change in the pathologic specimens. Transverse contrast-enhanced CT generally demonstrated an irregular multiloculated arterial wall, periaortic edema, a periaortic soft-tissue mass, or periaortic gas. ${ }^{8}$ Patients with aortic arch aneurysms-associated bronchial fistula or esophageal fistula were excluded in this study, because the former was difficult to diagnose as infectious aneurysms, and the latter was treated by a completely different surgical strategy. Patient profiles are shown in Table 1. Preoperative CT scan demonstrated that all patients had penetrating atherosclerotic ulcer (PAU) in the distal aortic arch, which formed saccular aneurysms (Figure 1). PAU was defined as a focal contrasted-filled outpouching of the aorta through intimal calcified plaque using CT scan. Four of 9 patients had preoperative hoarseness. All patients had ongoing fever before surgery. The duration from the infection onset was $36.6 \pm 56.9$ days (range, 0 day to 6 months). Preoperative blood culture was positive in 3 of 9 patients. Five of 9 


\section{Abbreviations and Acronyms \\ $\mathrm{CRP} \quad=\mathrm{C}$-reactive protein \\ CT = computed tomography \\ PAU = penetrating atherosclerotic ulcer \\ TAR $=$ total aortic arch replacement \\ TEVAR $=$ thoracic endovascular aortic repair}

patients had undergone antibiotic therapy before surgery, and the duration ranged from 9 days to 6 months.

The standardized surgical procedure of TAR used at Kobe University Graduate School of Medicine has been reported. ${ }^{2}$ Surgical indication and urgency were determined by the type of aneurysm (saccular) with clinical symptom (chest pain, back pain, and sudden development of hoarseness) and active infection (ongoing fever, increased white blood cell count, and C-reactive protein [CRP] level) despite the use of antibiotics. All patients underwent TAR on an urgent/emergency basis $(1.8 \pm 2.1$ days after admission). After cardiopulmonary bypass was established, tympanic temperature had decreased to $20^{\circ} \mathrm{C}$ to $23^{\circ} \mathrm{C}$, and rectal temperature was less than $30^{\circ} \mathrm{C}$, the aortic arch was opened and antegrade selective cerebral perfusion was started. The distal aortic arch or the descending aorta was transected at the distal clear level of the infected aneurysms, followed by debridement of the infected tissue and aneurysmal wall, and copious saline irrigation. Intraoperative Gram staining was performed in 6 of 9 patients, and resected aneurysm walls were subjected to both tissue culture and pathologic examinations in all patients. Intraoperative Gram staining was positive in 3 of 6 patients, and culture of resected aortic wall was positive for bacterial growth in 7 of 9 patients. A gelatin-impregnated quadrifurcated Dacron graft (Gelweave, Vascutek Ltd, Terumo Corp, Scotland, UK, or J Graft Shield Neo, Japan Lifeline, Tokyo, Japan) was used. Rifampicin soaking of the gelatin-sealed Dacron graft was performed in 8 of 9 patients. After completion of the distal anastomosis of the prosthetic graft, lower body circulation was restarted thorough a branch graft, and the tympanic/rectal temperature was rewarmed early to $33^{\circ} \mathrm{C}$. The proximal anastomosis of the graft was completed followed by coronary reperfusion. Finally, the aortic arch vessels were reconstructed. In 7 of 9 patients, the omental flap was prepared and installed around the prosthetic graft to separate the surrounding tissue after debridement.

Subsequently, the causative microorganisms were identified by blood culture or aortic wall culture and were as follows: Candida albicans, Pseudomonas aeruginosa, Edwardsiella tarda, Streptococcus dysgalactiae, Listeria monocytogenes, and Staphylococcus aureus (2 cases). Negative culture was obtained in 2 patients (numbers 5 and 6). Intravenous antibiotic therapy based on sensitivity data was continued for 6 weeks postoperatively, and prolonged antibiotic therapy was continued according to the clinical course (fever), blood test parameters (WBC and CRP levels), and CT imaging.

\section{Statistical Analysis}

Continuous variables were expressed as mean \pm standard deviation. Survival and freedom from recurrence of infection were assessed by the Kaplan-Meier method using SPSS software (SPSS Inc, Chicago, Ill).

\section{RESULTS}

Average operation time was $507.3 \pm 163.9$ minutes, cardiopulmonary bypass time was $199.7 \pm 50.7$ minutes, myocardial ischemic time was $92.0 \pm 16.7$ minutes, lower body circulatory arrest time was $66.7 \pm 13.8$ minutes, and antegrade selective cerebral perfusion time was $136.4 \pm 29.6$ minutes. Average minimum tympanic and rectal temperatures were $21.6^{\circ} \mathrm{C} \pm 1.3^{\circ} \mathrm{C}$ and $26.3^{\circ} \mathrm{C} \pm$ $1.4^{\circ} \mathrm{C}$, respectively. The 30-day mortality and in-hospital mortality were $0 \%$. Average duration of postoperative hospital stay was $47.0 \pm 33.8$ days. No newly developed neurologic deficits were observed. One patient had refractory methicillin-resistant Staphylococcus aureus pneumonia, followed by tracheostomy. Two patients (numbers 5 and 7) had iatrogenic hoarseness caused by radical debridement of infected aneurysmal walls, and 3 patients had atrial fibrillation. None of the patients experienced persistent bacteremia.

Follow-up was completed in all cases, and average duration of follow-up was $25.0 \pm 23.6$ months (range, 0.8-69.7 months). One late death (patient number 2) occurred 5 months after the operation and was caused by asphyxia. Freedom from recurrence of infection was $100 \%$ during the follow-up (Figure 2).

Representative findings of pathology of the resected aortic walls demonstrated infiltration of neutrophils, formation of abscess (Figure 3, $A$ and $B$ ), and the presence of gram-positive cocci by Gram staining (Figure 3, $C$ ).

\section{DISCUSSION}

Infected aortic aneurysm is a rare but formidable medical condition associated with mortality ranging from $4.3 \%$ to $36 \%{ }^{3,9,10}$ Weis-Muller and associates ${ }^{11}$ demonstrated that the mortality was highly dependent on the status of rupture at the time of surgery, but the ratio in patients with contained rupture was still as high as $30 \%$. There are few sporadic reports that have specifically focused on the infected aneurysms located in the aortic arch, with a reported mortality ranging from $0 \%$ to $10 \%{ }^{3,10}$ There is no known reliable strategy for the treatment of infected distal aortic arch aneurysms. The current study provided information regarding the clinical presentation of this sample of patients and their profiles, as well as satisfactory outcomes, including survival and freedom from recurrent infection.

Presenting symptoms are often nonspecific. All patients had consistent fever, and the final diagnosis was obtained by CT scan. Four of 9 patients (numbers 1, 2, 4, and 6) $(44.4 \%)$ had progressive hoarseness, and 7 patients had a history of chest and back pain. Tokmaji and colleagues ${ }^{12}$ demonstrated that preoperative progressive hoarseness was a rare clinical presentation, ${ }^{12}$ but in the patients in this study the incidence was as high as $44.4 \%$.

With regard to aortic pathology, although a recent report by Nathan and associates ${ }^{13}$ demonstrated PAU location in the aortic arch in 7\% and in the descending thoracic aorta in $62 \%$, all patients in this study had PAU with severe calcification in the distal aortic arch. Stellmes and associates ${ }^{7}$ also showed that PAU was a cause of aortic pathology in the native aortic infection. However, whether PAU is likely to be associated with infection remains controversial. 
TABLE 1. Patient profiles

\begin{tabular}{|c|c|c|c|c|c|c|c|c|c|c|c|c|c|}
\hline \multirow[b]{2}{*}{ No } & \multirow[b]{2}{*}{$\begin{array}{c}\text { Age, } \\
\mathbf{y}\end{array}$} & \multirow[b]{2}{*}{ Sex } & \multirow[b]{2}{*}{ DM } & \multirow{2}{*}{$\begin{array}{c}\text { Maximum } \\
\text { WBC } \\
\mu \mathrm{L}\end{array}$} & \multirow{2}{*}{$\begin{array}{c}\text { Maximum } \\
\text { CRP, } \\
\text { mg/dL }\end{array}$} & \multirow{2}{*}{$\begin{array}{c}\text { Clinical symptoms } \\
\text { except fever } \\
\text { and comorbidity }\end{array}$} & \multirow[b]{2}{*}{ Microorganism } & \multirow[b]{2}{*}{$\begin{array}{c}\text { Preoperative } \\
\text { antibiotics }\end{array}$} & \multirow{2}{*}{$\begin{array}{c}\text { Duration } \\
\text { on } \\
\text { antibiotics } \\
\end{array}$} & \multicolumn{3}{|c|}{ Culture } & \multirow{2}{*}{$\begin{array}{c}\text { Omenta } \\
\text { flap } \\
\text { grafting }\end{array}$} \\
\hline & & & & & & & & & & Blood & $\begin{array}{c}\text { Gram } \\
\text { staining }\end{array}$ & $\begin{array}{c}\text { Aortic } \\
\text { tissue }\end{array}$ & \\
\hline 1 & 61 & M & No & 8000 & 5.73 & $\begin{array}{l}\text { Hoarseness, chest } \\
\text { pain, iliopsoas } \\
\text { muscle abscess, } \\
\text { history of left } \\
\text { CIA aneurysm } \\
\text { (Salmonella) }\end{array}$ & $\begin{array}{l}\text { Candida } \\
\text { albicans }\end{array}$ & Yes & $\begin{array}{l}6 \text { mo after } \\
\quad \text { iliac } \\
\text { operation }\end{array}$ & Negative & NA & Positive & Yes \\
\hline 2 & 79 & M & No & 5700 & 0.89 & Hoarseness & $\begin{array}{r}\text { Pseudomonas } \\
\text { aeruginosa }\end{array}$ & Yes & $17 \mathrm{~d}$ & Negative & $\mathrm{NA}$ & Positive & No \\
\hline 3 & 79 & M & Yes & 12,200 & 17.6 & $\begin{array}{l}\text { Back pain } \\
\text { Laryngeal cancer } \\
\text { tracheostomy }\end{array}$ & $\begin{array}{l}\text { Edwardsiella } \\
\text { tarda }\end{array}$ & Yes & $12 \mathrm{~d}$ & Negative & $\begin{array}{c}\text { Positive } \\
\text { GPC }\end{array}$ & Positive & Yes \\
\hline 4 & 59 & $\mathrm{~F}$ & Yes & 14,700 & 20.6 & $\begin{array}{l}\text { General fatigue } \\
\text { Hoarseness }\end{array}$ & $\begin{array}{l}\text { Streptococcus } \\
\text { dysgalactiae }\end{array}$ & No & NA & Positive & Negative & Positive & Yes \\
\hline 5 & 64 & $\mathrm{~F}$ & No & 7400 & 17.8 & $\begin{array}{l}\text { Back pain } \\
\text { Infected AAA }\end{array}$ & Unknown & Yes & $9 \mathrm{~d}$ & Negative & Negative & Negative & Yes \\
\hline 6 & 79 & $\mathrm{~F}$ & No & 9400 & 15.1 & $\begin{array}{l}\text { Hoarseness, } \\
\text { back pain } \\
\text { CAD }\end{array}$ & Unknown & Yes & $18 \mathrm{~d}$ & Negative & Negative & Negative & Yes \\
\hline 7 & 75 & $\mathrm{~F}$ & Yes & 4300 & 10.1 & $\begin{array}{l}\text { Chest pain } \\
\text { Liver cirrhosis } \\
\text { Child-Pugh } \\
\text { type A, AF }\end{array}$ & $\begin{array}{l}\text { Listeria } \\
\quad \text { monocytogenes }\end{array}$ & No & NA & Positive & $\begin{array}{c}\text { Positive } \\
\text { GPR }\end{array}$ & Positive & Yes \\
\hline 8 & 84 & $\mathrm{~F}$ & No & 12,600 & 20.4 & $\begin{array}{l}\text { Back pain } \\
\text { Osteoporosis, } \\
\text { on steroid }\end{array}$ & $\begin{array}{l}\text { Staphylococcus } \\
\quad \text { aureus }\end{array}$ & No & NA & Positive & $\begin{array}{c}\text { Positive } \\
\text { GPC }\end{array}$ & Positive & Yes \\
\hline 9 & 74 & M & Yes & 17,600 & 6.1 & $\begin{array}{l}\text { Back pain } \\
\text { Left side } \\
\text { hemothorax }\end{array}$ & $S$ aureus & No & NA & Negative & NA & Positive & No \\
\hline
\end{tabular}

$\overline{A A A}$, Abdominal aortic aneurysm; $A F$, atrial fibrillation; $C A D$, coronary artery disease; $C I A$, common iliac artery; $C R P, \mathrm{C}$-reactive protein; $D M$, diabetes mellitus; $G P C$, gram-positive coccus; $G P R$, gram-positive rod; $N A$, not applicable; $W B C$, white blood cell.

In the current study, 2 of 9 patients (numbers 5 and 6) had a negative culture for both blood and resected pathology tissue sections, and in these cases the diagnosis was determined by clinical presentation, blood test, and CT imaging. Microscopic findings in these patients showed the formation of lymphoid follicle (number 5) and neutrophil filtration (number 6) in the resected aortic wall, which also suggested the presence of infection. Negative blood cultures have been reported in up to $25 \%$ of cases and may be due to antibiotic pretreatment or anaerobic organisms, which could also account for negative culture results of the resected pathology tissue sections. ${ }^{9,14}$ In the current study, we also speculate that the long duration of preoperative antibiotics therapy ranging from 9 days to 6 months in 5 of 9 patients caused the low incidence of bacteremia $(3 / 9,33.3 \%)$.

In the early reports, extra-anatomic bypass was selected just to avoid prosthetic graft infection. ${ }^{9}$ We believe that infected aneurysms in the aortic arch are not anatomically amenable to extra-anatomic bypass, and in situ replacement of TAR is the preferred method of selection as long as aggressive debridement of any infected tissue and the aneurysmal wall is performed. TAR for the treatment of infected aortic arch aneurysms is still a surgical challenge for organ protection because deep hypothermic circulatory arrest time is prolonged because of the requirement of the aggressive debridement with severe inflammation and more distal anastomosis. Indeed, average deep hypothermic arrest time was longer in the current study compared with our previous report $(66.6 \pm 13.8$ minutes vs $42.4 \pm 27.8$ minutes). ${ }^{2}$ Hsu and Lin $^{3}$ have reported excellent outcomes for the treatment of infected aortic arch in 10 patients. However, they applied retrograde cerebral perfusion under deep hypothermia for 80 minutes, and consequently 3 patients $(30 \%)$ had hypoxic encephalopathy. Antegrade selective cerebral perfusion is a preferable brain-protection method under prolonged circulatory arrest time.

Previous reports showed a recurrence of infection even after eradication by resection of the infected aortic wall and 


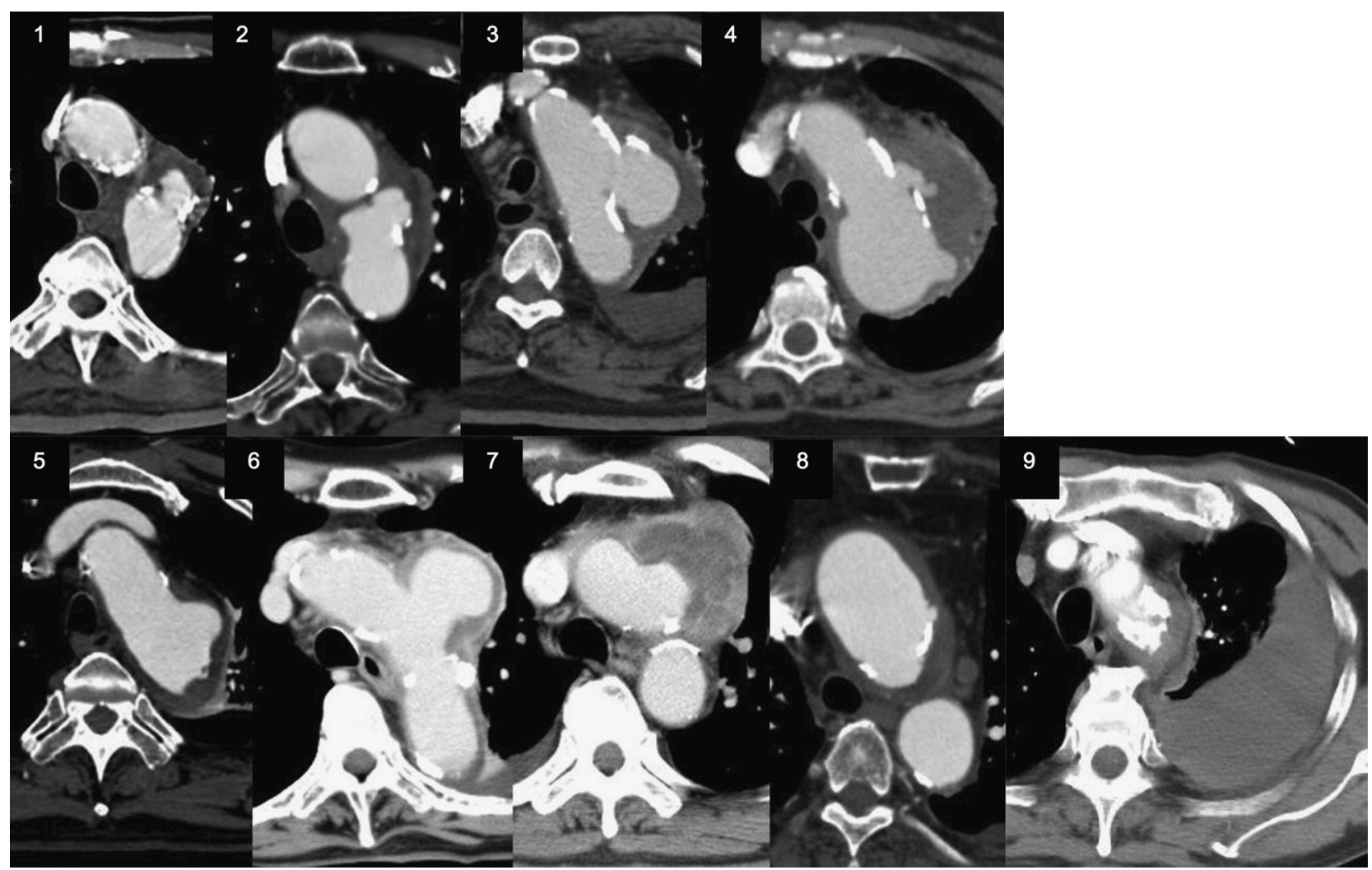

FIGURE 1. Preoperative findings of CT scan. All patients had PAU with calcification in the distal aortic arch, which formed saccular aneurysms. The aneurysm of patient number 8 was growing in a caudal direction onto the pulmonary trunk. The aneurysm of patient number 9 ruptured into the left pleural cavity with the formation of a hemothorax.

in situ replacement using a prosthetic graft. Some reports advocated that covering the prosthetic graft with an omental flap around it decreased the risk of recurrence of infection during follow-up. ${ }^{10,15,16}$ Although we prefer to apply the omental flap in every case unless there is a history of laparotomy (patient number 9), 1 patient (number 2) did not undergo omental flap grafting because we did not suspect the presence of infection because there were no positive data for infection in the blood test results (elevated WBC counts and serum CRP concentration) before surgery.
In this case, infection of the aortic aneurysm was identified postoperatively by aortic wall culture.

TEVAR is an emerging minimally invasive treatment. In a recent report, Stellmes and associates ${ }^{7}$ demonstrated the efficacy of TEVAR in 6 patients for suspected aortic infection in an emergency treatment situation. In their study, TEVAR was performed as a bridge treatment in 3 of the 6 patients, and eventually open conversion was required. We believe that TEVAR is useful as an alternative treatment for patients with circulatory collapse or fistula
Survival

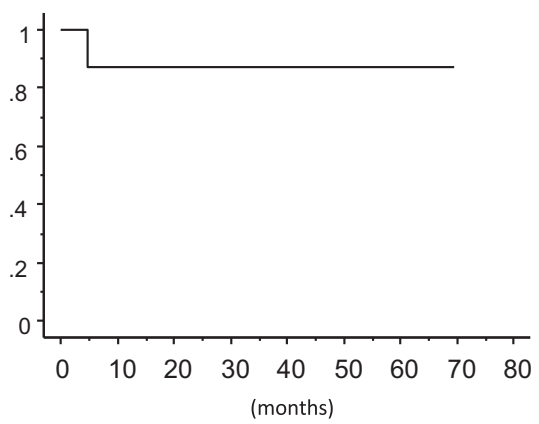

Freedom from recurrence of infection

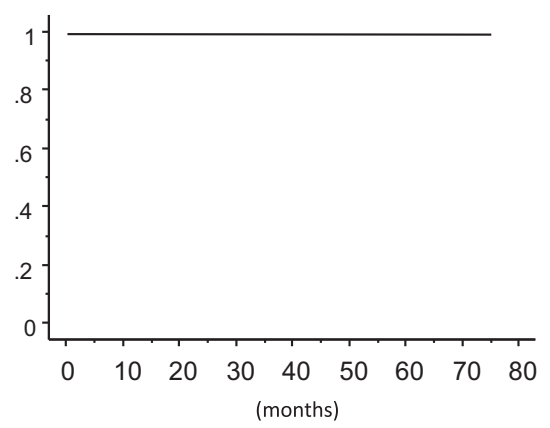

FIGURE 2. Survival and freedom from recurrence of infection. The survival curve (left) and freedom from recurrence of infection (right). 

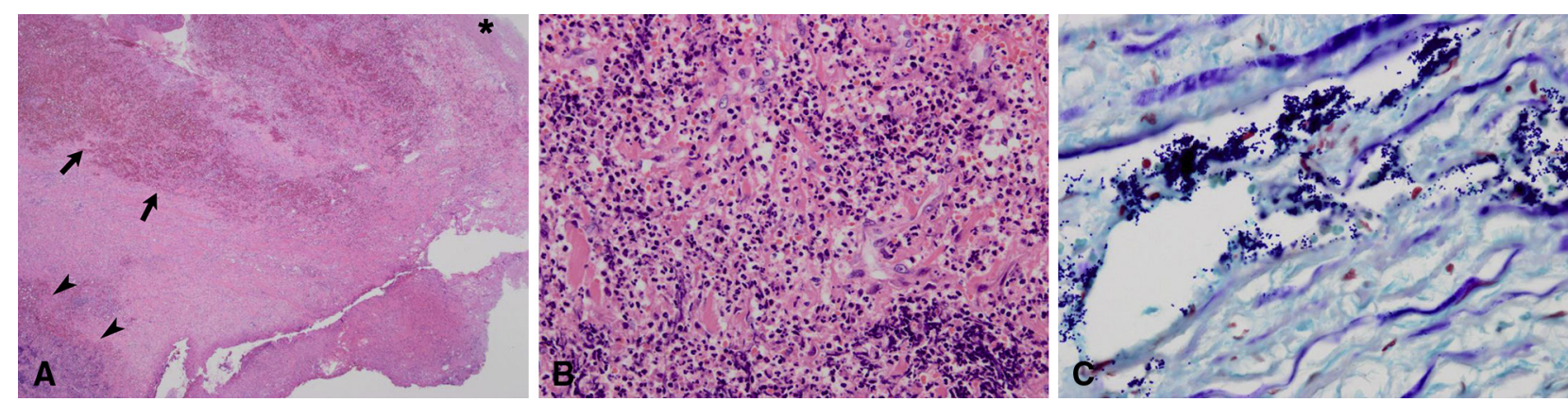

FIGURE 3. Representative findings of pathology of resected aortic walls. A, Hematoxylin-eosin staining (patient number 8). Asterisk shows the media of the aortic wall. Arrowheads demonstrate the abscess formation, and arrows demonstrate hemorrhage in the outgrowth adventitia. B, Hematoxylin-eosin staining in large scale (patient number 8) demonstrates infiltration of neutrophils and lymphocyte growth. C, Gram staining (patient number 9) demonstrates the intramural presence of gram-positive cocci.

to the adjacent tissue, such as the bronchus or the esophagus, ${ }^{17,18}$ to improve a patient's condition while awaiting open repair.

\section{Study Limitations}

This was a retrospective study from a single center. The mean follow-up period was short $(25.0 \pm 23.6$ months; range, 0.8-69.7 months).

\section{CONCLUSIONS}

This study provided information regarding the clinical presentation, the patients' profile, and the aortic pathology of infected aortic arch aneurysms. Surgical treatment with a combination of radical debridement followed by in situ TAR with omental flap grafting was a reliable procedure.

\section{References}

1. Amano J, Kuwano H, Yokomise H. Thoracic and cardiovascular surgery in Japan during 2011: annual report by The Japanese Association for Thoracic Surgery. Gen Thorac Cardiovasc Surg. 2013;61:578-607.

2. Okada K, Omura A, Kano H, Sakamoto T, Tanaka A, Inoue T, et al. Recent advancements of total aortic arch replacement. J Thorac Cardiovasc Surg. 2012;144:139-45.

3. Hsu RB, Lin FY. Surgery for infected aneurysm of the aortic arch. J Thorac Cardiovasc Surg. 2007;134:1157-62.

4. Tamenishi A, Usui A, Oshima H, Ueda Y. Entirely polytetrafluoroethylene coating for pacemaker system contact dermatitis. Interact Cardiovasc Thorac Surg. 2008;7:275-7.

5. Kan CD, Yen HT, Kan CB, Yang YJ. The feasibility of endovascular aortic repair strategy in treating infected aortic aneurysms. J Vasc Surg. 2012;55:55-60.

6. Kritpracha B, Premprabha D, Sungsiri J, Tantarattanapong W, Rookkapan S, Juntarapatin P. Endovascular therapy for infected aortic aneurysms. J Vasc Surg. 2011;54:1259-65.
7. Stellmes A, Von AR, Derungs U, Dick F, Makaloski V, Do DD, et al. Thoracic endovascular aortic repair as emergency therapy despite suspected aortic infection. Interact Cardiovasc Thorac Surg. 2013;16:459-64.

8. Lee WK, Mossop PJ, Little AF, Fitt GJ, Vrazas JI, Hoang JK, et al. Infected (mycotic) aneurysms: spectrum of imaging appearances and management. Radiographics. 2008;28:1853-68.

9. Muller BT, Wegener OR, Grabitz K, Pillny M, Thomas L, Sandmann W. Mycotic aneurysms of the thoracic and abdominal aorta and iliac arteries: experience with anatomic and extra-anatomic repair in 33 cases. J Vasc Surg. 2001;33:106-13.

10. Uchida N, Katayama A, Tamura K, Miwa S, Masatsugu K, Sueda T. In situ replacement for mycotic aneurysms on the thoracic and abdominal aorta using rifampicin-bonded grafting and omental pedicle grafting. Ann Thorac Surg. 2012;93:438-42.

11. Weis-Muller BT, Rascanu C, Sagban A, Grabitz K, Godehardt E, Sandmann W. Single-center experience with open surgical treatment of 36 infected aneurysms of the thoracic, thoracoabdominal, and abdominal aorta. Ann Vasc Surg. 2011;25: 1020-5.

12. Tokmaji G, Gosev I, Kumamaru KK, Bolman RM III. Mycotic aneurysm of the aortic arch presenting with left vocal cord palsy. Ann Thorac Surg. 2013;96: $302-5$.

13. Nathan DP, Boonn W, Lai E, Wang GJ, Desai N, Woo EY, et al. Presentation, complications, and natural history of penetrating atherosclerotic ulcer disease. J Vasc Surg. 2012;55:10-5.

14. Gross C, Harringer W, Mair R, Wimmer-Greinecker G, Klima U, Brucke P. Mycotic aneurysms of the thoracic aorta. Eur J Cardiothorac Surg. 1994;8: 135-8.

15. Coselli JS, Crawford ES. Primary aortoesophageal fistula from aortic aneurysm: successful surgical treatment by use of omental pedicle graft. J Vasc Surg. 1990; 12:269-77.

16. Kuniyoshi Y, Koja K, Miyagi K, Uezu T, Yamashiro S, Arakaki K. Graft for mycotic thoracic aortic aneurysm: omental wrapping to prevent infection. Asian Cardiovasc Thorac Ann. 2005;13:11-6.

17. Kubota S, Shiiya N, Shingu Y, Wakasa S, Ooka T, Tachibana T, et al. Surgical strategy for aortoesophageal fistula in the endovascular era. Gen Thorac Cardiovasc Surg. 2013;61:560-4.

18. Munakata H, Yamanaka K, Okada K, Okita Y. Successful surgical treatment of aortoesophageal fistula after emergency thoracic endovascular aortic repair: aggressive debridement including esophageal resection and extended aortic replacement. J Thorac Cardiovasc Surg. 2013;146:235-7. 